\title{
Sewage Sludge Biochar Effects on Phytopathogenic Fungi and Beneficial Microorganisms
}

\author{
Alyson Silva de Araujo ${ }^{1}$ \\ http://orcid.org/0000-0002-3919-7221 \\ Luiz Eduardo Bassay Blum ${ }^{2}$ \\ http://orcid.org/0000-0002-3968-6615
}

\section{Doyglas Vinícius Nunes Andrade ${ }^{1}$}

https://orcid.org/0000-0002-6145-1249

\section{Pedro Batista da Silva Júnior ${ }^{1}$}

https://orcid.org/0000-0003-2973-2152

\section{Cícero Célio de Figueiredo ${ }^{1 *}$}

http://orcid.org/0000-0002-7496-0261

\begin{abstract}
${ }^{1}$ University of Brasília, Faculty of Agronomy and Veterinary Medicine, Brasília, DF, Brazil; 2University of Brasília, Department of Plant Pathology, Brasília, DF, Brazil.
\end{abstract}

Editor-in-Chief: Alexandre Rasi Aoki

Associate Editor: Ana Cláudia Barana

Received: 2021.04.24; Accepted: 2021.07.21.

*Correspondence: cicerocf@unb.br; Tel.: +55-61-31077465 (C.C.F.)

\section{HIGHLIGHTS}

- Sewage sludge biochar (SSB) controls different phytopathogens.

- SSB has a direct effect on the mycelial growth of phytopathogenic fungi.

- Control of phytopathogens in low concentrations (up to $0.8 \%$ ) of SSB.

\begin{abstract}
Biochar $(\mathrm{BCH})$ is a solid product, rich in carbon, obtained by heating biomass under controlled conditions of oxygenation, in a process known as pyrolysis. Its benefits are associated with improvements to the physical, chemical and biological properties of soil. Furthermore, $\mathrm{BCH}$ can affect the growth of phytopathogenic microorganisms. Despite research advances in this area, there is still a lack of information on the effect of $\mathrm{BCH}$ concentration on different soilborne microorganisms. This work evaluated the direct effect of sewage sludge biochar (SSB) on the in vitro growth of different soilborne fungi. Eight phytopathogens [Fusarium oxysporum, F. oxysporum f. sp. lycopersici (CEN 1456), Macrophomina phaseolina (429), Sclerotinia sclerotiorum, S. sclerotiorum (CEN 1147), Sclerotium rolfsii (CEN 216), Sclerotium cepivorum (CEN 1357), Rhizoctonia solani] were evaluated. Additionally, a biological control agent [Trichoderma afroharzianum (T-22)] was also studied. Microorganisms were subjected to growth in PDA (Potato-DextroseAgar) culture medium enriched with SSB. Biochars, produced at 300 and $500{ }^{\circ} \mathrm{C}$, were applied at different doses: 0.0 (control), 0.2, 0.4, 0.6, 0.8 and 1.0 (g of SSB/100 ml of PDA). Biochars showed inhibitory effects on the mycelial growth of the different fungi evaluated. It was observed that there is a certain specificity of biochar concentration that must be evaluated for the control of phytopathogens. In most cases, the 0.4 and
\end{abstract}


$0.6 \%$ concentrations had a greater inhibitory effect on phytopathogens and did not affect the biological control agent. Therefore, SSB proved to be a promising product for the control of different soilborne phytopathogens.

Keywords: Biosolids; black carbon; pyrolysis; mycelial growth; biological control.

\section{INTRODUCTION}

Biochar $(\mathrm{BCH})$ is a solid material, rich in carbon $(\mathrm{C})[1,2]$, obtained via the thermal treatment of biomasses under controlled oxygenation conditions, in a process called pyrolysis [3,4]. The multifunctionality of $\mathrm{BCH}$ has aroused great interest in the scientific community around the world. In agriculture, $\mathrm{BCH}$ has been evaluated as a fertilizer and a soil conditioner, with several benefits for soil health.

Biochar can also control plant pathogens. Different mechanisms have been used to explain this inhibitory action of $\mathrm{BCH}$. Biochar features various organic compounds that can individually or together suppress or stimulate soilborne microorganisms [5, 6]. The main compounds identified in biochars that have adverse effects on microorganism growth and survival include ethylene glycol and propylene glycol, hydroxypropionic and hydroxybutyric acids benzoic acid and o-cresol, quinones (resorcinol and hydroquinone) and 2phenoxyethanol [7, 8]. Biochars produced from eucalyptus wood and crop residues had two organic compounds in common: lactic acid and glycolic acid [9]. Both organic acids are known to have fungicidal activity $[10,11]$. Recently, it was demonstrated that biochar also has a priming effect on the gene expression of plants, positively regulating the pathways and genes involved in defense and growth. According to Jaiswal and coauthors [12], the main compounds involved in this biochar function include jasmonic acid, brassinosteroids, cytokines, auxin, flavonoids and phenylpropanoids.

The presence of fulvic and humic acids in $\mathrm{BCH}$ can also increase the resistance of plants to pathogens. These organic acids increased the accumulation of phenolic compounds and flavonoids related to disease resistance in grape plants [13]. The antifungal activity of these acids has also been previously demonstrated, being able to inhibit up to $68 \%$ of the hyphae growth of Calonectria pseudonaviculata [14]. Dissolved organic matter, formed by different organic molecules including some humic substances, when released from the biochar can modify the structure of the microbial community [15].

In addition, the effect of $\mathrm{BCH}$ on the soil microbial structure and diversity has favored certain groups of microorganisms associated with promoting plant growth, disease suppression and other possible ecological roles [16]. The interaction of $\mathrm{BCH}$ with the soil microbiota was able to stimulate the development of beneficial microorganisms of the genera Pseudomonas, Bacillus and Trichoderma [17]. These microorganisms controlled the incidence of colon rot on roots of the physic nut plants (Jatropha curcas L.), caused by Lasiodiplodia theobromae, and promoted the growth of the plant [18]. Thus, by favoring beneficial microorganisms in the soil, the use of $\mathrm{BCH}$ is a promising alternative in the management of plant diseases with greater advantages compared to the use of chemical fungicides. Among the beneficial microorganisms, Trichoderma spp. may have a synergistic effect when combined with $\mathrm{BCH}$ for the control of soilborne pathogenic fungi [19]. BCH can increase the survival and growth of Trichoderma spp. populations [7, 20]. Trichoderma species are widely recognized for their ability to stimulate plant growth and productivity [21], in addition to being among the most studied microorganisms and used as biocontrol agents for plant diseases worldwide.

The concentration and availability of nutrients (fertilizer function), the retention/degradation capacity of organic [22] and inorganic pollutants [23], the alkalizing power [24], the porosity and water retention [25] are some functions of biochars that are affected by the type of raw material and pyrolysis conditions, and can interfere with the action of $\mathrm{BCH}$ as a pathogen control agent. For example, the $\mathrm{pH}$ of $\mathrm{BCH}$ can shift the composition and activity of soil microbial communities [26]. Similarly, changes in electrical conductivity (EC) of the medium can alter the survival rates of fungi [27]. Therefore, variations in EC observed in different sewage sludge biochars (SSBs) [28] can increase the survival and spread of certain phytopathogens. These changes promoted by pyrolysis also affect the interactions between biochar and soil microorganisms, affecting pathogen development and the severity of plant diseases [29,30]. Therefore, the specificity of the material to control each microorganism must be observed.

Even with the growing number of studies on biochars of different raw materials, in the specific case of SSB there is still no information available on the effect of a wide range of SSB doses obtained at different temperatures on various soilborne pathogenic fungi. This work sought to evaluate the effect of SSB on the in vitro growth of soilborne microorganisms, including both phytopathogenic fungi and beneficial microorganisms for plant development. 


\section{MATERIAL AND METHODS}

\section{Production and characterization of the biochars}

Biochars were produced from SS samples collected at the wastewater treatment plant (WWTP) belonging to the Environmental Sanitation Company of the Federal District, Brasília, DF, Brazil. This WWTP utilizes a tertiary treatment system. In this system not only does anaerobic sewage decomposition occur, but specific nutrients such as $\mathrm{P}$ and $\mathrm{N}$ are removed from the liquid effluent by a coagulation process using aluminum salts. Therefore, these nutrients remain in the final SS biomass. Contrarily, in this process potassium $(\mathrm{K})$ is not removed from the liquid effluent, resulting in a SS that is poor in this nutrient.

For biochar preparation, SS samples were air-dried (to approximately $10 \%$ moisture content). Thereafter, SS samples were crushed and passed through an $8 \mathrm{~mm}$ sieve followed by pyrolysis at $300^{\circ} \mathrm{C}$ and $500^{\circ} \mathrm{C}$ in a muffle furnace (Linn Elektro Therm, Eschenfelden, Alemanha) measuring 610 x 610 x $590 \mathrm{~mm}$ (width $\mathrm{x}$ depth $x$ height). Sewage sludge samples were placed in a 30-liter metal container adapted to the internal space of the oven containing a gas and bio-oil outlet system, and a mechanism to prevent the flow of oxygen. For temperature control, a K-type penetration probe (model MTK-15, São Paulo, Brazil) was coupled to a digital thermometer (KT-160A, Swidnica, Poland). The oven operated with an average temperature increase rate of $2.5^{\circ} \mathrm{C} \mathrm{min}-1$, totaling 110 and $190 \mathrm{~min}$ to reach the respective temperatures (300 and $500^{\circ} \mathrm{C}$ ), and a residence time of 300 minutes.

The physical and chemical properties of SS and SSB are shown in Table 1. Carbon (C) and nitrogen (N) were determined using an elemental analyzer (PE 2400, series II CHNS/O, PerkinElmer, Norwalk, USA). The $\mathrm{pH}$ was determined in a $0.01 \mathrm{M} \mathrm{CaCl}_{2}$ solution, using a 1:5 (w/v) biochar:solution ratio suspension [31]. Humic substances (HS) were determined by fractionation via solubility in an alkaline and acidic medium [32]. Humic substances were extracted with a $\mathrm{NaOH} 0.1 \mathrm{M}$ solution and the $\mathrm{C}$ content was determined according to Yeomans and Bremner [33]. Macronutrient contents [P, K, calcium (Ca), magnesium (Mg), sulfur (S)] were determined after nitroperchloric digestion [34]. Phosphrous was quantified by the molybdovanadate method, $\mathrm{K}$ by flame photometry and the others $(\mathrm{Ca}, \mathrm{Mg}$ and $\mathrm{S}$ ) were determined by inductively coupled plasma optical emission spectrometry (ICP-OES) (ICPE-9000, Shimadzu, Japan). Complementary information on the methodologies used for the physical-chemical characterization of SS and biochars is available in Figueiredo and coauthors [28] and Figueiredo and coauthors [23]. 
Table 1 Characteristics of the sewage sludge and the biochars.

\begin{tabular}{|c|c|c|c|}
\hline Property & Sewage sludge & Biochar 300 & Biochar 500 \\
\hline Moisture (\%) & $10.62 \pm 1.56$ & $4.26 \pm 0.23$ & $3.17 \pm 0.05$ \\
\hline Volatile matter (\%) & $48.25 \pm 1.36$ & $41.75 \pm 2.47$ & $29.74 \pm 1.40$ \\
\hline Ash (\%) & $39.33 \pm 2.38$ & $48.27 \pm 1.08$ & $60.05 \pm 0.51$ \\
\hline Fixed carbon (\%) & $1.79 \pm 0.52$ & $5.72 \pm 1.55$ & $7.04 \pm 0.86$ \\
\hline Inert carbon (\%) & $3.23 \pm 0.39$ & $2.86 \pm 0.34$ & $3.18 \pm 0.08$ \\
\hline Total carbon (\%) & $18.58 \pm 0.26$ & $19.92 \pm 0.28$ & $18.65 \pm 0.18$ \\
\hline TOC (\%) & $17.45 \pm 0.85$ & $18.61 \pm 0.09$ & $16.90 \pm 0.85$ \\
\hline TOM (\%) & $30.09 \pm 1.47$ & $32.09 \pm 0.15$ & $29.13 \pm 1.47$ \\
\hline Fulvic acid $\left(\mathrm{g} \mathrm{kg}^{-1}\right)$ & $24.10 \pm 0.58$ & $23.89 \pm 0.33$ & $15.12 \pm 0.50$ \\
\hline Humic acid $\left(\mathrm{g} \mathrm{kg}^{-1}\right)$ & $8.45 \pm 0.39$ & $7.51 \pm 0.11$ & $2.92 \pm 0.05$ \\
\hline Humin $\left(\mathrm{g} \mathrm{kg}^{-1}\right)$ & $146.28 \pm 3.00$ & $139.90 \pm 1.21$ & $143.49 \pm 2.85$ \\
\hline $\mathrm{N}(\%)$ & $3.99 \pm 0.05$ & $5.05 \pm 1.16$ & $5.03 \pm 0.88$ \\
\hline $\mathrm{C} / \mathrm{N}$ & $4.66 \pm 0.02$ & $3.95 \pm 0.96$ & $3.71 \pm 0.77$ \\
\hline $\mathrm{pH}\left(\mathrm{CaCl}_{2}\right)$ & $5.48 \pm 0.02$ & $6.04 \pm 0.04$ & $6.50 \pm 0.01$ \\
\hline CEC $\left(\mathrm{mmol} \mathrm{L}^{-1}\right)$ & $286.67 \pm 1.53$ & $265.00 \pm 2.00$ & $224.67 \pm 1.53$ \\
\hline$P\left(g_{k g}^{-1}\right)$ & $22.81 \pm 1.84$ & $30.94 \pm 1.97$ & $33.74 \pm 2.12$ \\
\hline $\mathrm{K}\left(\mathrm{g} \mathrm{kg}^{-1}\right)$ & 0 & 0 & 0 \\
\hline $\mathrm{Ca}\left(\mathrm{g} \mathrm{kg}^{-1}\right)$ & $13.17 \pm 0.21$ & $11.33 \pm 0.15$ & $19.47 \pm 0.47$ \\
\hline $\operatorname{Mg}\left(g_{k g}{ }^{-1}\right)$ & $2.53 \pm 0.06$ & $2.77 \pm 0.06$ & $3.13 \pm 0.06$ \\
\hline$S\left(g_{k g}^{-1}\right)$ & $13.70 \pm 0$ & $15.10 \pm 0$ & $23.13 \pm 0.46$ \\
\hline$B\left(\mathrm{mg} \mathrm{kg}^{-1}\right)$ & 0 & 0 & 0 \\
\hline $\mathrm{Cu}\left(\mathrm{mg} \mathrm{kg}^{-1}\right)$ & $100.00 \pm 0$ & $113.33 \pm 5.77$ & $130.00 \pm 10.00$ \\
\hline $\mathrm{Fe}\left(\mathrm{g} \mathrm{kg}^{-1}\right)$ & $15.40 \pm 0.17$ & $16.40 \pm 0.10$ & $16.93 \pm 0.06$ \\
\hline $\operatorname{Mn}\left(\mathrm{mg} \mathrm{kg}^{-1}\right)$ & $100 \pm 0$ & $100 \pm 0$ & $103.33 \pm 5.77$ \\
\hline $\mathrm{Zn}\left(\mathrm{mg} \mathrm{kg}^{-1}\right)$ & $400.00 \pm 0$ & $503.33 \pm 5.77$ & $433.33 \pm 57.74$ \\
\hline Yield (\%) & - & $82.48 \pm 1.10$ & $64.32 \pm 0.60$ \\
\hline
\end{tabular}

Average values \pm standard deviation $(n=3)$; TOC: total organic carbon; TOM: total organic matter; CEC: cation exchange capacity.

\section{Bioassay: biochar and in vitro growth of soilborne fungi}

Biochar samples were macerated in a mortar and later passed through a $500 \mu \mathrm{m}$ mesh sieve. The culture medium was produced from Potato-Dextrose-Agar (PDA - Acumedia®, Michigan, USA), formulated by adopting $39 \mathrm{~g}$ of synthetic PDA in 1 liter of distilled water, and then autoclaved.

Different concentrations of biochars produced at 300 and $500 \circ \mathrm{C}$ were tested. The following concentrations were assessed: $0.0,0.2,0.4,0.6,0.8$ and 1.0 (g of BCH / $100 \mathrm{ml}$ of PDA). The BCH concentration of $0 \mathrm{~g}$ per $100 \mathrm{~mL}$ of PDA was defined as the control. The culture media was poured into Petri dishes, using $25 \mathrm{~mL}$ per plate as a standard. The fungi were picked from seven-day old colonies, using a 6 $\mathrm{mm}$ diameter perforator, and adopting one disc per plate. The experiment was conducted in a completely randomized design, with five replications.

The experiment evaluated the mycelial growth of nine soilborne fungi, including six distinct genera, eight phytopathogenic microorganisms and one fungus widely used in the biological control of plant diseases. The phytopathogenic fungi evaluated in the experiment were: Fusarium oxysporum, F. oxysporum f. sp. lycopersici (strain CEN 1456), Macrophomina phaseolina (strain 429), Sclerotinia sclerotiorum, S. sclerotiorum (strain CEN 1147), Sclerotium rolfsii (strain CEN 216), Sclerotium cepivorum (strain CEN 1357) and Rhizoctonia solani. These phytopathogenic fungi were chosen because they are capable of causing diseases in the main plants cultivated in the central region of Brazil, in addition to attacking a wide range of hosts. Trichoderma afroharzianum (strain T-22) was studied as a beneficial microorganism due its wide use as a biological control agent of several plant diseases.

The microorganisms were subjected to incubation at room temperature (ranging from 22 to $30{ }^{\circ} \mathrm{C}$ ) and a 12 hour photoperiod. The exception was Sclerotium cepivorum (strain CEN 1357), in which incubation took place in an incubator (model EL202/3LED) at $20 \stackrel{\circ}{\circ}$ and 12 hour photoperiod. 
Evaluations started 24 hours after setting up the experiment, with daily measurements of mycelial growth (mm), for 4 to 10 days, using a digital caliper (150 mm/MTX).

The percentage of control that biochar had on the different fungi was calculated according to the following equation:

$$
\text { (\%) Control }=\frac{T(0)-T(m) \times 100}{T(0)}
$$

Where, $\mathrm{T}(0)$ is the diameter of the fungus mycelial growth $(\mathrm{mm})$ in the culture medium without SSB; and $\mathrm{T}(\mathrm{m})$ is the diameter of the fungus mycelial growth $(\mathrm{mm})$ in the culture medium with SSB at the concentration of greatest microorganism inhibition.

\section{Statistical analyses}

Data was analyzed using a one-way ANOVA, followed by Tukey's HSD test $(P<0.05)$ as a post-hoc method to detect statistically significant differences among all treatments. All statistical analyses were performed using the software IBM SPSS Statistics, version 23.0 [35], and graphs were elaborated using the SigmaPlot software, version 12.5 [36].

\section{RESULTS AND DISCUSSION}

Figure 2 shows colonization of Sclerotium rolfsii in the presence and absence of biochar. The fungus mycelial growth is identified by the white color on the Petri dishes. In the control treatment, the entire Petri dish was colonized by the pathogen. On the other hand, mycelial growth was reduced in the presence of biochar. Therefore, the enrichment of culture media with SSB reduced mycelial growth of different soilborne fungi, demonstrating a direct effect on the microorganisms (Figure 1). Results of the present study showed that there is a certain specificity of the biochar concentration on the growth of both phytopathogenic and beneficial fungi. 


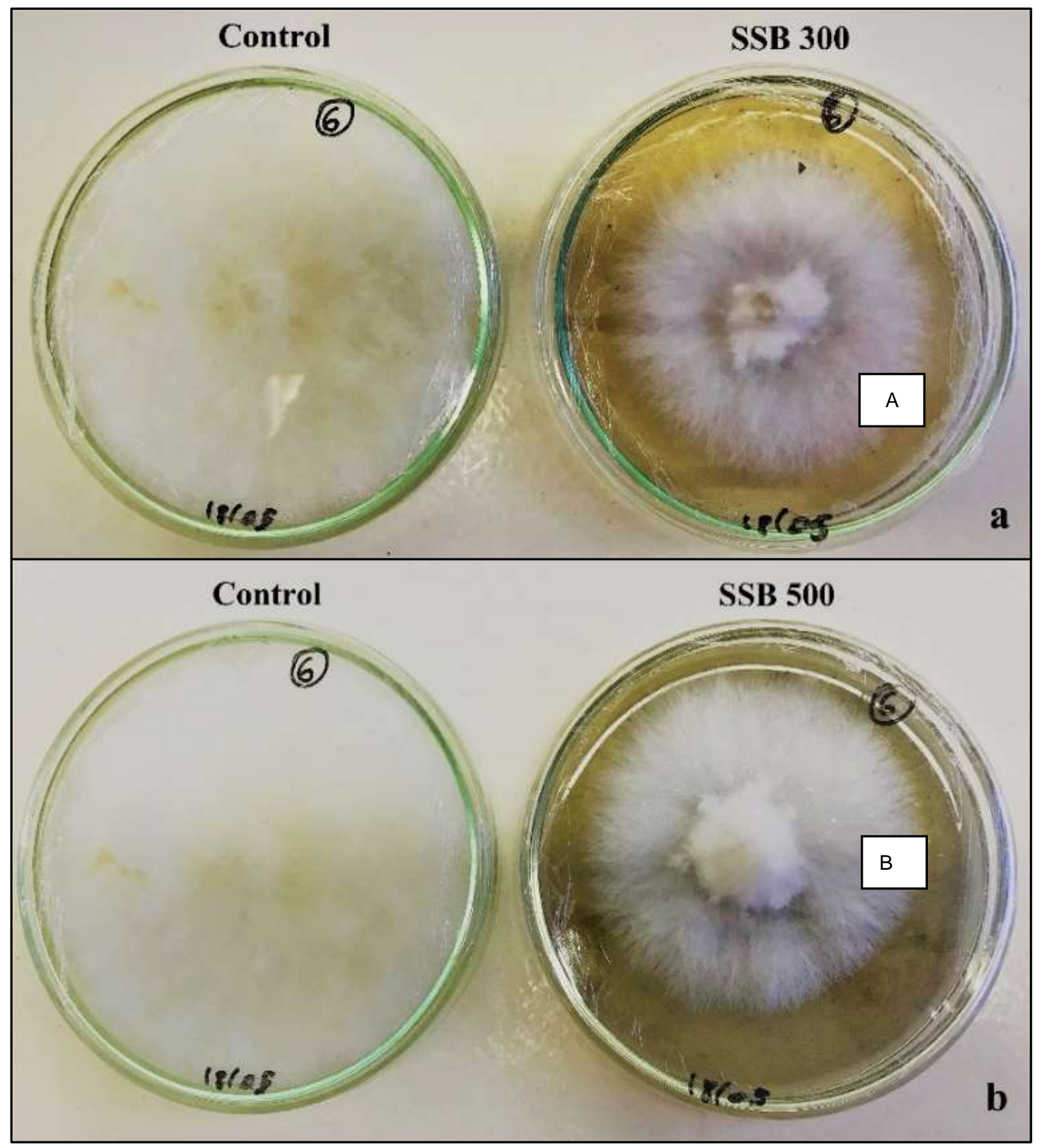

Figure 1. Inhibition of Sclerotium rolfsii mycelial growth caused by the enrichment of the PDA culture medium with sewage sludge biochar produced at $300^{\circ} \mathrm{C}(\mathrm{A})$ and $500^{\circ} \mathrm{C}(\mathrm{B})$.

The effects of SSB on mycelial growth of different species of soilborne fungi are presented in Figures 2, 3 and 4 . In these figures, the microorganisms were grouped according to their scientific classification, first the phytopathogens and finally the beneficial microorganism. Figure 2 shows the effects of SSB on fungi of the phylum Ascomycota, (F. oxysporum, F. oxysporum f. sp. lycopersici (CEN 1456) and M. phaseolina (strain 429)), in Figure 3 the phylum Ascomycota, order Helotiales (S. sclerotiorum, S. sclerotiorum (CEN 1147 ) and S. cepivorum (CEN 1357) and in Figure 4 the fungi of the phylum Basidiomycota (S. rolfsii (CEN 216) and $R$. solani) and the biological control agent $T$. afroharzianum (strain T-22), phylum Ascomycota. 
Biochar 300
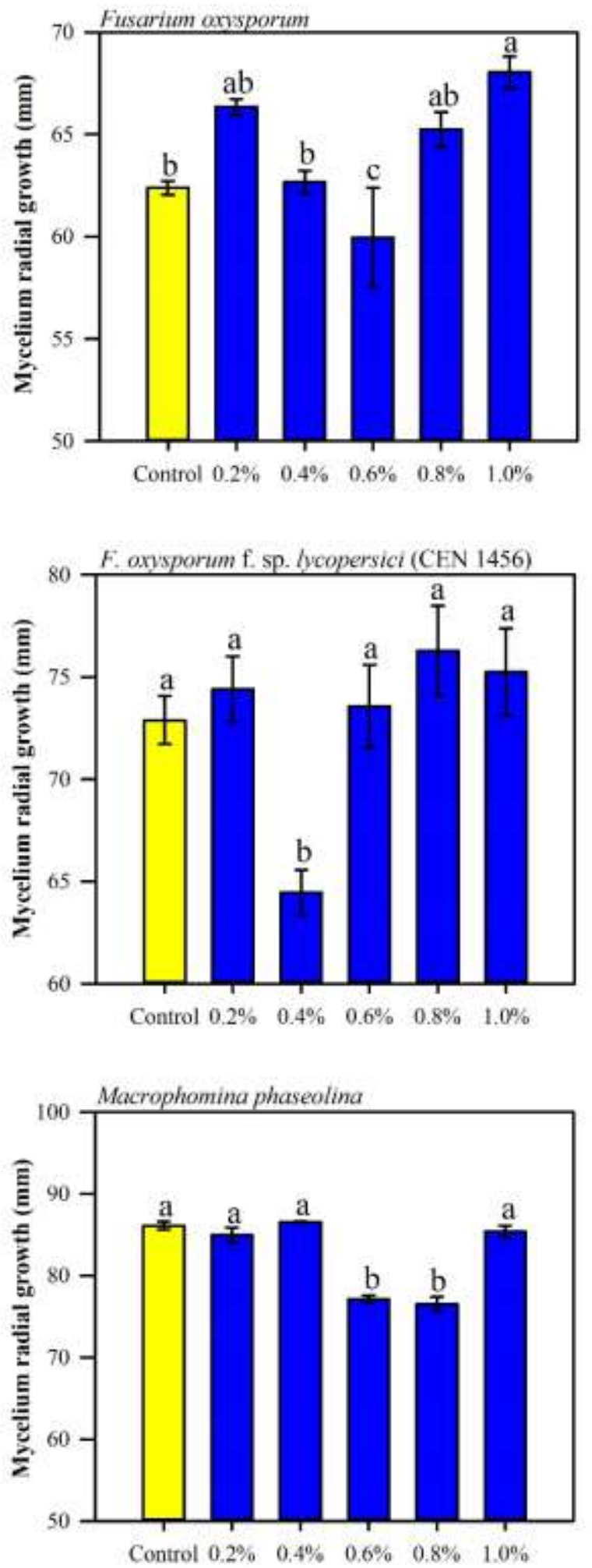

Treatments
Biochar 500
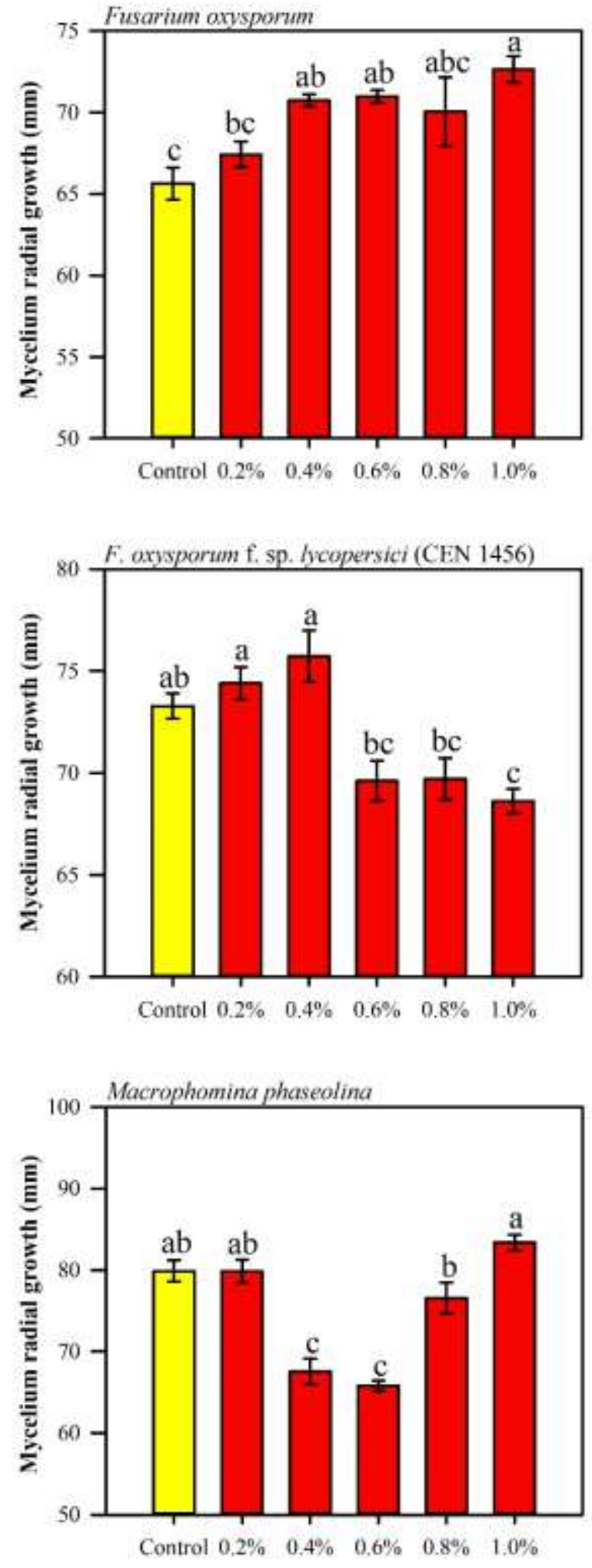

Treatments

Figure 2. In vitro mycelial growth of Fusarium oxysporum, F. oxysporum f. sp. lycopersici (CEN 1456) and Macrophomina phaseolina (strain 429) in the presence of biochars obtained at $300^{\circ} \mathrm{C}$ and $500^{\circ} \mathrm{C}$. Equal letters indicate no significant difference by the Tukey test $(p<0.05)$. The error bars indicate the standard deviation of the mean $(n=5)$. 
Biochar 300
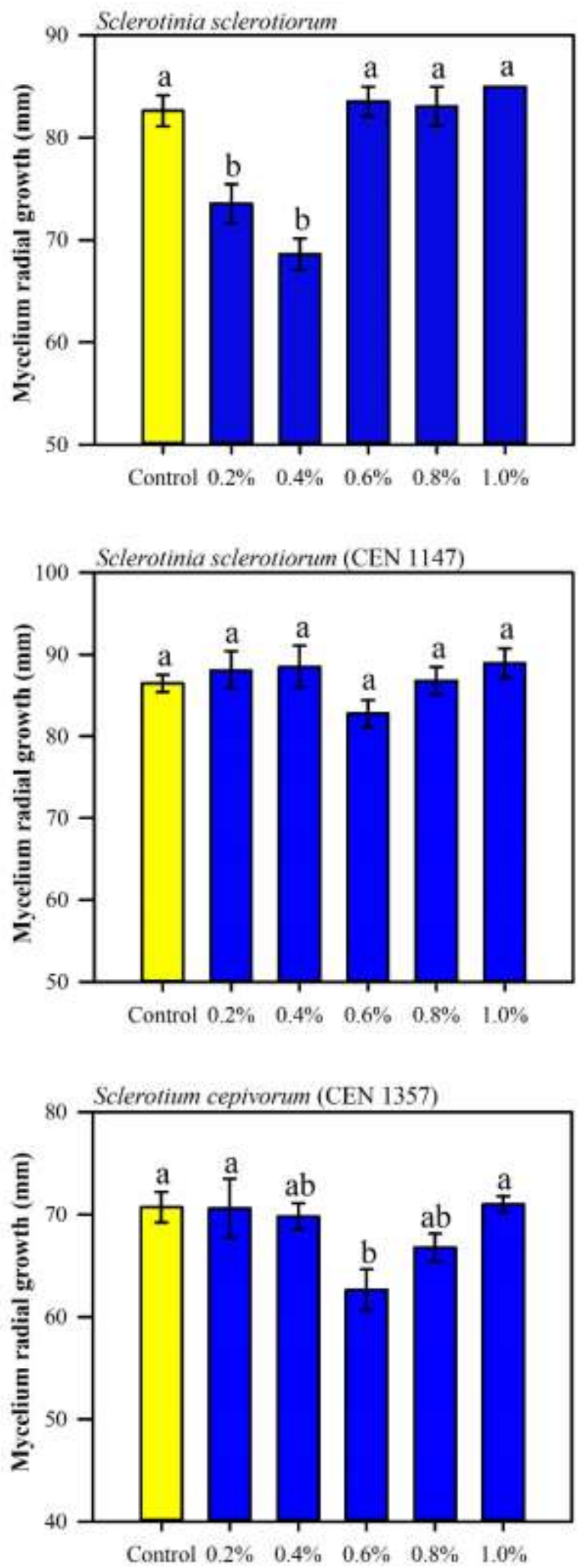

Treatments
Biochar 500
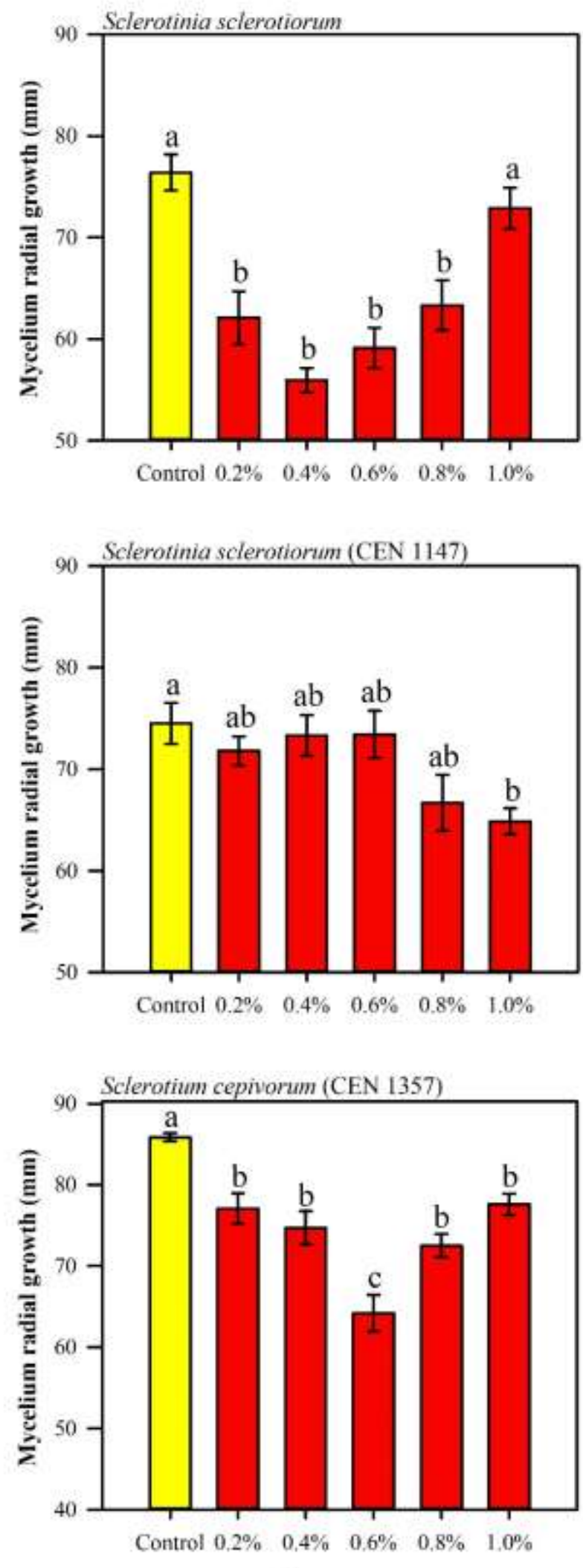

Treatments

Figure 3 In vitro mycelial growth of Sclerotinia sclerotiorum, S. sclerotiorum (CEN 1147) and Sclerotium cepivorum (CEN 1357) in the presence of biochars obtained at $300^{\circ} \mathrm{C}$ and $500^{\circ} \mathrm{C}$. Equal letters indicate no significant difference by the Tukey test $(p<0.05)$. The error bars indicate the standard deviation of the mean $(n=5)$. 
Biochar 300
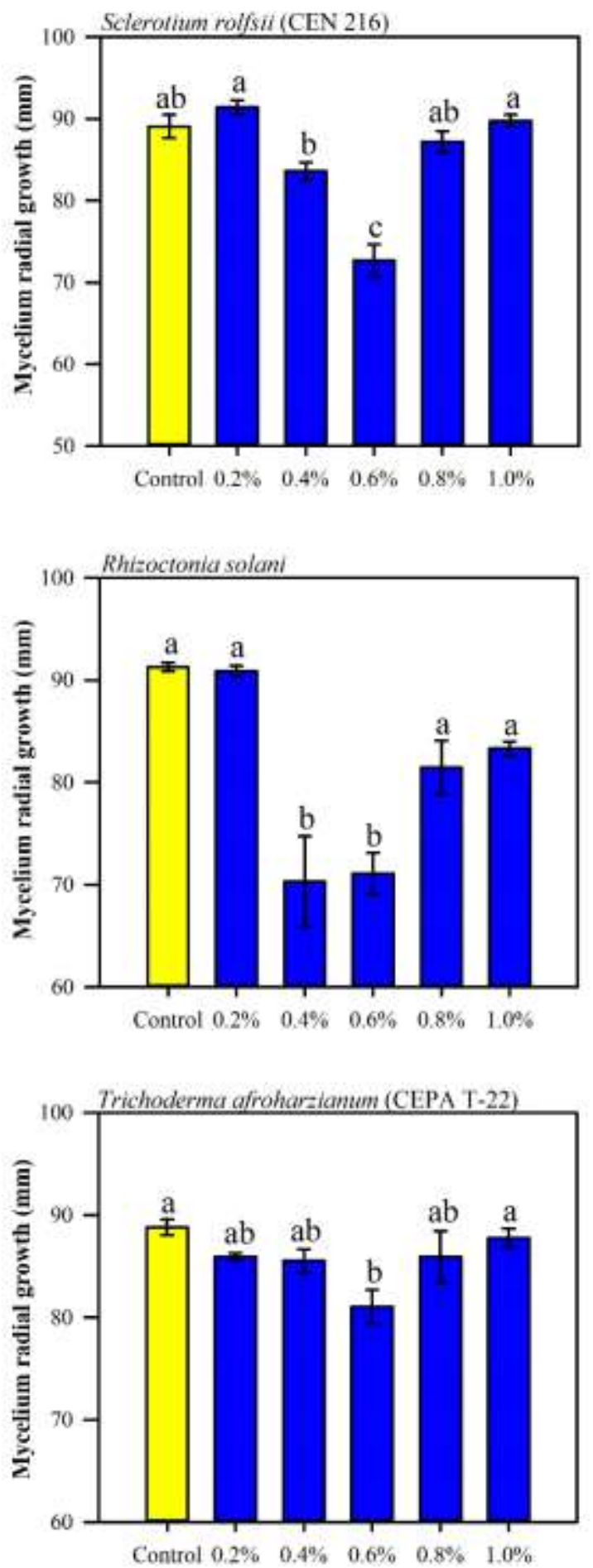

Treatments
Biochar 500
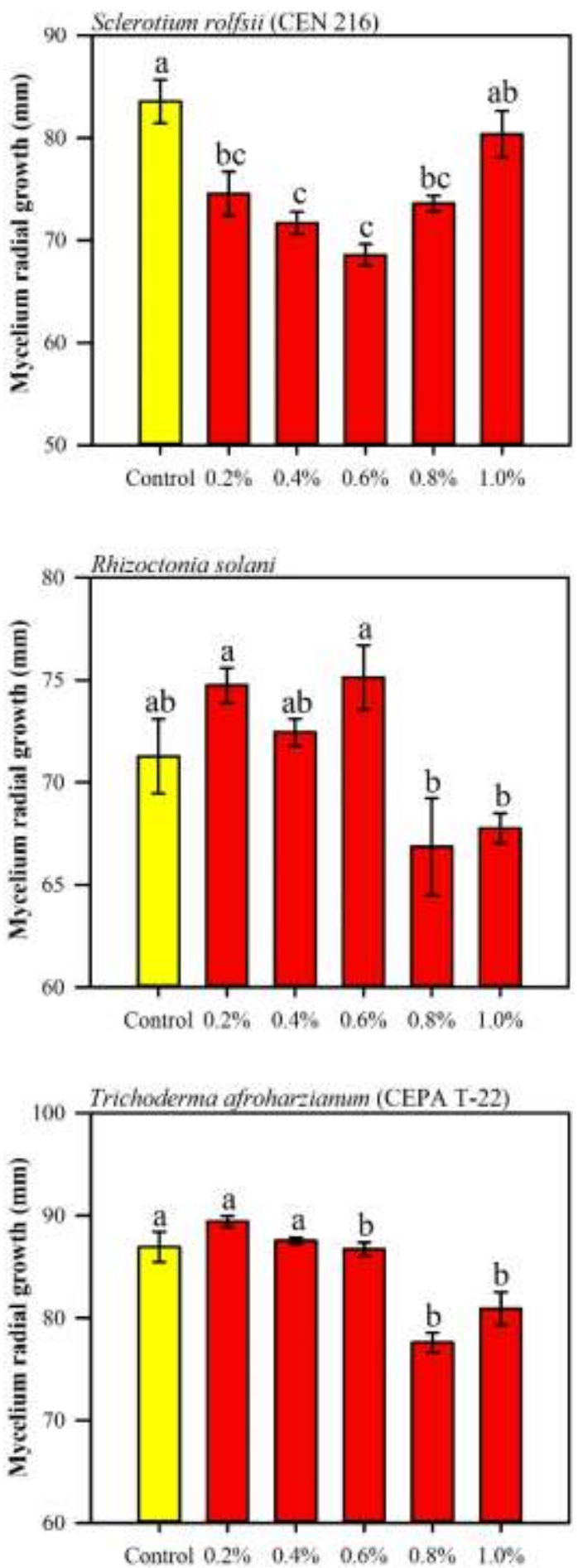

Treatments

Figure 4. In vitro mycelial growth of Sclerotium rolfsii (CEN 216), Rhizoctonia solani and Trichoderma afroharzianum (strain T-22) in the presence of biochars obtained at $300{ }^{\circ} \mathrm{C}$ and $500{ }^{\circ} \mathrm{C}$. Equal letters indicate no significant difference by the Tukey test $(p<0.05)$. The error bars indicate the standard deviation of the mean $(n=5)$.

Based on the pyrolysis temperature, the SSB produced at $300^{\circ} \mathrm{C}$ showed the ability to inhibit $F$. oxysporum. However, when the same raw material was pyrolyzed at $500{ }^{\circ} \mathrm{C}$ the SSB did not affect fungus mycelial growth. On the other hand, in the evaluation of S. sclerotiorum (CEN 1147), only the BC 500 affected microorganism growth. The results of the present study corroborate those obtained by Rogovska and coauthors [37], who demonstrated variations in the control capacity of Fusarium virguliforme when biochars produced from different raw materials and temperatures were tested, highlighting the importance of evaluating different doses of $\mathrm{BCH}$ to control phytopathogenic microorganisms. Rogovska and coauthors [37] 
also highlighted the direct effect of organic compounds released from the biochar and changes in soil microbiological and enzymatic properties as mechanisms to control phytopathogens.

In general, the sewage sludge biochars showed in vitro inhibitory capacity to control different soilborne fungi. The 0.4 and $0.6 \%$ concentrations of SSB were the most promising to control phytopathogenic fungi. However, in most of the tests carried out with microorganisms, it was observed that in SSB concentrations greater than $0.8 \%$ there is a loss of inhibition capacity and even a probable stimulus of fungi mycelial growth. In general, it was also found that low concentrations of SSB, less than $0.4 \%$, had no effect on the fungi mycelial growth in both phytopathogens and the beneficial microorganism. However, the $0.4 \%$ concentration promoted the mycelial growth of $F$. oxysporum.

In the present study, the control pattern of phytopathogens was similar to studies with biochars obtained from multiple raw materials that demonstrated a response curve (biochar dosage versus fungus growth) in a "U" shape, with intermediate doses responsible for the best disease suppression results [38, 29, 39]. These authors reported that the highest doses of $\mathrm{BCH}$ were responsible for the highest incidence of disease. This response pattern in which low doses of $\mathrm{BCH}$ reduce the disease and high doses stimulate disease has been described as the hormesis effect [29]. Each pathosystem (host-pathogen) probably had a specific relationship with the dose and the type of biochar used.

Under field or pot conditions, biochar doses to control phytopathogens typically range from 0 to $20 \%$. Zwart and Kim [38] evaluated doses of pinewood biochar (0 to $20 \%$ in relation to the pot's volume) and observed that the lowest dose (5\%) was responsible for the greatest disease control, and that higher doses (10 and 20\%) had a more negligible effect or possible expansion of the necrotic lesion caused by Phytophthora cactorum on red maple seedlings (Acer rubrum). Similarly, Jaiswal and coauthors [29] demonstrated that biochars produced from eucalyptus wood chips and vegetable residues, pyrolyzed at 350 and $600{ }^{\circ} \mathrm{C}$, had a suppressive effect on damping-off caused by $R$. solani in cucumber when concentrations up to $1 \%$ (mass/mass) were used. Doses of $3 \%$ increased damping-off by up to $82 \%$ compared to the control.

The present study demonstrated that the direct effect of SSB on the mycelial growth of soilborne microorganisms occurs in doses ranging from 0 to $1 \%$ (mass/volume). After an extensive literature review, Frenkel and coauthors [39] concluded that there is still no predefined $\mathrm{BCH}$ dose that can be adopted in different pathosystems. Furthermore, further studies of individual plant-pathogen-biochar systems should be performed. In addition, these authors demonstrated the importance of understanding the mechanisms involved in the suppression and promotion of diseases after the application of biochar to develop efficient protocols for this purpose.

There are few studies in vitro focused on the use of SSB and its direct effect on phytopathogens. Microorganism suppression by biochar is usually addressed by involving the indirect mechanisms associated with disease control in plants, including: induced resistance, the alteration of beneficial microbial communities, the content and supply of nutrients, biotoxins and compounds similar to phytohormones derived from biochar [40]. Results involving the direct in vitro effect of SSB on phytopathogen control were addressed by Araujo and coauthors [19], demonstrating the inhibition of mycelial growth of $M$. phaseolina when doses of 0.5 and $1.0 \%$ (mass/volume) were adopted. When SSB was used in combination with Trichoderma it presented a synergistic effect, providing greater development of bean plants (Phaseolus vulgaris) [19] and soybeans (Glycine max) [41].

The present work highlights SSB use in plant disease control since it has properties that directly impact the growth of different genera of phytopathogenic soilborne fungi. These results indicate the potential of applying SSB to control soilborne fungi, reducing the use of chemicals and favoring more sustainable agriculture.

\section{Microorganism control versus pyrolysis temperature}

Table 2 shows the control promoted by SSB on different microorganisms. In general, the percentage of control ranged from $6.19 \%$ in $R$. solani to $26.75 \%$ in $S$. sclerotiorum. The highest percentages of control (Table 2), associated with the use of BLE 300, are reported for fungi $R$. solani and S. rolfsii (CEN 216) with mycelial growth inhibition of $23 \%$ and $18.41 \%$, respectively. Biochar 500 provided greater inhibition potential of the fungi S. sclerotiorum and S. cepivorum (CEN 1357) with control percentages of $26.75 \%$ and $25.22 \%$, respectively. 
Table 2. Percentage of control caused by the use of sewage sludge biochar.

\begin{tabular}{lcc}
\hline \multirow{2}{*}{ Microorganism } & \multicolumn{2}{c}{ Percentage of control } \\
\cline { 2 - 3 } & Biochar $\mathbf{3 0 0}$ & Biochar 500 \\
\hline Fusarium oxysporum & 8.70 & 0.00 \\
Fusarium oxysporum f. sp. lycopersici (CEN 1456) & 11.58 & 6.37 \\
Macrophomina phaseolina (429) & 11.17 & 17.63 \\
Sclerotinia sclerotiorum & 16.91 & 26.75 \\
Sclerotinia sclerotiorum (CEN 1147) & 0.00 & 12.95 \\
Sclerotium cepivorum (CEN 1357) & 11.41 & 25.22 \\
Sclerotium rolfsii (CEN 216) & 18.41 & 17.92 \\
Rhizoctonia solani & 23.00 & 6.19 \\
Trichoderma afroharzianum (Strain T-22) & 8.75 & 10.74 \\
\hline
\end{tabular}

The results obtained in tests with fungi of the genus Fusarium demonstrated the ability for direct control exercised by SSBs. However, the increase in $\mathrm{pH}$, described by Gatch and coauthors [42] as one of the mechanisms to suppress $F$. oxysporum f. sp. spinaciae, does not apply to the results obtained with SSB in the present study. This is because the highest percentages of Fusarium inhibition occurred with Biochar 300, a material with a lower $\mathrm{pH}$ compared to Biochar 500. For example, Zong and coauthors [43] reported that SSB application caused an increase in $\mathrm{pH}$ in both clayey and sandy soils. Consequently, the possible effect of the $\mathrm{pH}$ increase caused by SSB, suppressing the mycelial growth of the microorganisms studied in this work, could be associated with assays utilizing the fungi $S$. sclerotiorum, S. sclerotiorum (CEN 1147), $M$. phaseolina (429), S. cepivorum (CEN 1357) and T. afroharzianum (strain T-22), in which the use of Biochar 500 resulted in greater control capacity.

\section{Physical-chemical characteristics that affect the inhibiting capacity of biochars}

Biochars showed considerable levels of calcium in their composition (Table 1). In vitro tests involving products containing calcium demonstrated significant inhibition of the mycelial growth of $P$. cinnamomi, as well as a reduction in the production of sporangia, chlamydospores and zoospores when millimolar $\mathrm{Ca}^{2+}$ concentrations were used [44]. In the present work, biochars also presented a variety of micronutrients in their composition, especially zinc, manganese and copper. The use of fertilizer containing micronutrients, including zinc and manganese, has been proposed as an alternative to control Verticillium dahliae Kleb. [45]. These authors demonstrated by in vitro assay that these chemicals were responsible for mycelial growth inhibition, reduction of melanin production and microsclerosis of $V$. dahliae, in addition to associating this effect to the factor of certain micronutrients being also observed in inorganic fungicides. In the present study, biochars showed characteristics with the potential to inhibit mycelial growth (direct effect) of five genera of phytopathogenic fungi.

Another physical-chemical characteristic observed in biochars is the variation in electrical conductivity (EC) according to the pyrolysis temperature $[46,47]$. In the present work, enrichment of the BDA culture medium with increasing doses of Biochar 300 and Biochar 500 may have caused an increase in the EC of the medium where the fungi grew. Consequently, there was a reduction in the efficiency of SSB for controlling certain phytopathogens, especially when higher doses were applied. Kong and coauthros [27] reported an increase in the survival rate of different fungi of the genus Phytophthora in response to the EC increase in the environment.

In the present study, the range of fungi growth response to the application of SSB was lower than that presented in other studies. Copley and coauthors [48] observed that enrichment of the culture medium with different concentrations (1, 3 and $5 \%$ ) of wood bark biochar produced at $700{ }^{\circ} \mathrm{C}$ provided an increase in the linear extension and growth rate of $R$. solani compared to the culture medium without the addition of biochar. This result was attributed to several organic compounds present in the wood bark biochar extract, probably metabolized by the phytopathogen.

Biochars were also able to control the growth of fungi of the genus Fusarium, whose inhibition capacity ranged from 6.37 to $11.58 \%$ (Table 2). Heck and coauthors [49] evaluated different trials for the control of $F$. oxysporum f. sp. cubense. In one of the experiments, the authors observed that the addition of sawdust biochar from Eucalyptus spp. to the culture medium did not have a significant inhibitory effect on mycelial 
growth of the fungus. In contrast, in their second trial the authors observed that volatile compounds released by $\mathrm{BCH}$ were able to reduce the mycelial growth of $F$. oxysporum f. sp. cubense.

The wide variety of organic compounds present in $\mathrm{BCH}$ s has been highlighted as having an inhibitory effect on certain soilborne fungi microorganisms [5,6]. Among the main organic compounds identified in biochars that have suppressive potential, the following are frequently highlighted: ethylene glycol and propylene glycol, hydroxypropionic and hydroxybutyric acids, benzoic acid and o-cresol, quinones (resorcinol and hydroquinone) and 2-phenoxyethanol [7, 8]. Lactic acid and glycolic acid, observed in biochars produced from eucalyptus wood and plant residues [9], are widely recognized for their fungicidal activity [10, 11].

In the present study SSBs produced at lower pyrolysis temperatures $\left(300^{\circ} \mathrm{C}\right)$ had higher proportions of volatile matter. The presence of volatile organic compounds (VOCs) can directly impact soil microorganisms [26] and can directly inhibit/stimulate microbial and plant processes [5]. Consequently, the greater inhibitory effect caused by Biochar 300 in certain phytopathogens studied in this work may be associated with the greater fraction of volatile solids present in its composition.

Fulvic and humic acids in $\mathrm{BCH}$ can promote plant disease control. The antifungal activity of these acids inhibited up to $68 \%$ of the hyphae growth of Calonectria pseudonaviculata [14]. Due to higher levels of fulvic and humic acids in the present work, Biochar 300 demonstrated greater control capacity (from 8.70 to $23 \%$ ) over four microorganisms in relation to Biochar 500, being: F. oxysporum, F. oxysporum f. sp. lycopersici (CEN 1456), S. rolfsii (CEN 216) and $R$. solani. Dissolved organic matter, formed by different compounds and including some humic substances, when released from biochar can modify the microbial community structure [15].

In biochars of the present study, the carbon content and its fractions were affected by the pyrolysis temperature. By assessing this aspect and developing soilborne microorganisms, Rogovska and coauthors [37] associated a lower incidence of root rot caused by $F$. virguliforme to the higher levels of fixed carbon present in the biochar. However, the results of the present study did not follow this pattern, where the $\mathrm{BCH}$ produced at $500{ }^{\circ} \mathrm{C}$ presented a higher fixed carbon content than that at $300{ }^{\circ} \mathrm{C}$, did not more efficiently control phytopathogens, especially when evaluated against Fusarium.

Both biochars produced at 300 and $500^{\circ} \mathrm{C}$ were efficient in controlling $R$. solani, with mycelial growth inhibition percentage varying from 6.19 to $23 \%$ (Table 2). To control this pathogen, biochar obtained at a lower temperature has been shown to be more efficient when adopting biochar concentrations ranging from 0.4 to $0.6 \%$. Jaiswal and coauthors [9] demonstrated that biochars produced from eucalyptus wood and plant residues also have a direct effect on the control of $R$. solani, with the highest doses (ranging from 0 to $3 \%$ ) responsible for the best inhibition results. However, the authors indicated that even though biochars have antifungal compounds, such as lactic and glycolic acids, the response curve of the direct toxicity of biochars in relation to the pathogen may not be the trend observed in conditions involving the plant, soil, biochar, dose and pathogen.

The evaluation of $T$. afroharzianum (strain T-22) (Figure 4) demonstrated that SSB has inhibitory activity on fungus mycelial growth at specific doses. This result was verified with the dose of $0.6 \%$ of Biochar 300 , and 0.8 and $1.0 \%$ of Biochar 500 . However, the doses that showed the greatest inhibitory effect on phytopathogenic fungi did not interfere with the mycelial growth of such a biological control agent, especially when evaluating the effect of the biochar produced at $500^{\circ} \mathrm{C}$.

The impact on beneficial fungi, such as those of the genus Trichoderma, in a medium enriched with biochar is of paramount importance for the adoption of plant disease control practices which have less impact on the environment, in which different alternatives are adopted in consortium. Araujo and coauthors [19] observed that the synergistic effect of SSB in combination with Trichoderma enhances the in vitro control of M. phaseolina and also promotes the greater development of bean plants (Phaseolus vulgaris, cv. BRS Estilo) in the presence or absence of the phytopathogen. The combined use of biochar with Trichoderma has demonstrated that in addition to the greater development and productivity of cultivated plants [41], this synergism leads to improved soil fertility, greater absorption of nutrients and promotes the growth of fungal and bacterial populations in the rhizosphere [50].

In the present study, SSB showed good potential for the control of different phytopathogenic microorganisms, however its use for this purpose must be based on the specificity of each fungus and the concentration that best meets this objective. 


\section{CONCLUSIONS}

The present study allows for concluding that the effect of SSB on controlling phytopathogenic fungi is specific for microorganism types and pyrolysis temperatures. For example, biochar produced at $300{ }^{\circ} \mathrm{C}$ was efficient in controlling all evaluated fungi, except Sclerotinia sclerotiorum (CEN 1147). Similarly, Biochar 500 was efficient in controlling phytopathogenic fungi, except for $F$. oxysporum. Despite the interference in mycelial growth of the biological control agent $T$. afroharzianum, the biochar concentrations that inhibited most phytopathogenic fungi did not negatively interfere with the beneficial microorganism. In general, regardless of the pyrolysis temperature, the use of SSB in low concentrations (up to $0.8 \%$ ) has a direct effect on the control of different phytopathogenic fungi. Specifically, the 0.4 and $0.6 \%$ concentrations of SSB can be recommended for controlling soilborne pathogenic fungi. Biochar 500 should be preferable for controlling S. sclerotiorum and $R$. solani since it promoted more than $25 \%$ of control. The information obtained on the specificity between doses and fungi will support the development of strategies for using biochar in field conditions.

Conflicts of interest: The authors declare no conflict of interest.

\section{REFERENCES}

1. Marshall J, Muhlack R, Morton BJ, Dunnigan L, Chittleborough D, Kwong CW. Pyrolysis temperature effects on biochar-water interactions and application for improved water holding capacity in vineyard soils. Soil Syst. 2019;3(27):1-14. https://doi.org/10.3390/soilsystems3020027

2. Tian $Y$, Cui L, Lin Q, Li G, Zhao X. The sewage sludge biochar at low pyrolysis temperature had better improvement in urban soil and turf grass. Agronomy. 2019;9(156):1-13. https://doi.org/10.3390/agronomy9030156

3. Sohi SP. Carbon storage with benefits. Science. 2012;338:1034-5. https://doi.org/10.1126/science.1225987

4. Samolada MC, Zabaniotou AA. Comparative assessment of municipal sewage sludge incineration, gasification and pyrolysis for a sustainable sludge-to-energy management in Greece. Waste Manage. 2014;34:411-20. https://doi.org/10.1016/j.was-man.2013.11.003

5. Spokas KA, Novak JM, Stewart CE, Cantrell KB, Uchimiya M, Dusaire MG, et al. Qualitative analysis of volatile $\begin{array}{llll}\text { organic compounds } \quad \text { 2011;85(5):869-82. } & \text { Chemosphere. }\end{array}$ https://doi.org/10.1016/j.chemosphere.2011.06.108.

6. Sun D, Meng J, Liang H, Yang E, Huang Y, Chen W, et al. Effect of volatile organic compounds absorbed to fresh biochar on survival of Bacillus mucilaginosus and structure of soil microbial communities. J Soils Sediment. 2015;15(2):271-81. https://doi.org/10.1007/s11368-014-0996-z

7. Graber ER, Harel YM, Kolton M, Cytryn E, Silber A, David DR, et al. Biochar impact on development and productivity of pepper and tomato grown in fertigated soilless media. Plant Soil. 2010;337(1-2):481-96. https://doi.org/10.1007/s11104-010-0544-6

8. Buss $W$, Mašek $O$, Graham $M$, Wüst $D$. Inherent organic compounds in biochar - Their content, composition and potential toxic effects. J Environ Manage. 2015;156:150-7. https://doi.org/10.1016/j.jenvman.2015.0-3.035

9. Jaiswal AK, Frenkel O, Elad Y, Lew B, Graber ER. Non-monotonic influence of biochar dose on bean seedling growth and susceptibility to Rhizoctonia solani: the "Shifted Rmax-Effect". Plant Soil. 2015;395:125-40. https://doi.org/10.1007/s11104-014-2331-2

10. Abbasi PA, Lazarovits G, Jabaji-Hare, S. Detection of high concentrations of organic acids in fish emulsion and their role in pathogen or disease suppression. Phytopathology. 2009;99:274-81. https://doi.org/10.1094/PHYTO-99-30274

11. Hassan R, El-Kadi S, Sand M. Effect of some organic acids on some fungal growth and their toxins production. Int J Adv Biol. 2015;2(1):1-11.

12. Jaiswal AK, Alkan N, Elad Y, Sela N, Philosoph AM, Graber ER, et al. Molecular insights into biochar-mediated plant growth promotion and systemic resistance in tomato against Fusarium crown and root rot disease. Sci Rep. 2020;10(13934):1-15. https://doi.org/10.1038/s41598-020-70882-6

13. Xu D, Deng Y, Xi P, Yu G, Wang Q, Zeng Q, et al. Fulvic acid-induced disease resistance to Botrytis cinerea in table grapes may be mediated by regulating phenylpropanoid metabolism. Food Chem. 2019;286:226-33. https://doi.org/10.1016/j.foodchem.2019.02.015

14. Samavat S, Samavat S, Wyka SA. Humic and fulvic acids against boxwood blight disease caused by Calonectria pseudonaviculata. For Pathol. 2020;50(2):1-8. https://doi.org/10.1111/efp.12583

15. Zhang $P$, Huang $P, X u X$, Sun H, Jiang B, Liao Y. Spectroscopic and molecular characterization of biochar-derived dissolved organic matter and the associations with soil microbial responses. Sci Total Environ. 2020;708(134619),111. https://doi.org/10.1016/j.scitotenv.2019.134619 
16. Jaiswal AK, Elad Y, Cytryn E, Graber ER, Frenkel O. Activating biochar by manipulating the bacterial and fungal microbiome through pre-conditioning. New Phytol. 2018;219(1):363-77. https://doi.org/10.1111/nph.15042

17. Contreras-Cornejo HA, Macías-Rodríguez L, Del-Val E, Larsen J. Ecological functions of Trichoderma spp. and their secondary metabolites in the rhizosphere: interactions with plants. FEMS Microbiol Ecol. 2016;92(4):1-21. https://doi.org/10.1093/femsec/fiw036

18. Latha P, Anand T, Prakasam V, Jonathan El, Paramathma M, Samiyappan R. Combining Pseudomonas, Bacillus and Trichoderma strains with organic amendments and micronutrient to enhance suppression of collar and root rot disease in physic nut. Appl Soil Ecol. 2011;49:215-23. https://doi.org/10.1016/j.apsoil.2011.0-5.003.

19. De Araujo AS, Blum LEB, de Figueiredo, CC. Biochar and Trichoderma harzianum for the control of Macrophomina phaseolina. Braz Arch Biol Technol. 2019;62(e19180259):1-10. https://doi.org/10.1590/1678-4324-2019180259

20. Vecstaudza D, Grantina-levina L, Makarenkova G, Kasparinskis R, Selga T, Steinberga V, et al. The impact of wood-derived biochar on the survival of Trichoderma spp. and growth of Secale cereale L. in sandy soil. Biocontrol Sci Techn. 2018;28(4):341-58. https://doi.org/10.1080/09583157.2018.1450488

21. Singh BN, Singh A, Singh GS, Dwivedi P. Potential role of Trichoderma asperellum T42 strain in growth of pea plant for sustainable agriculture. J Pure Appl Microbiol. 2015;9:1069-74. https://doi.org/10.13140/RG.2.1.4845.3201

22. Zhang X, Wang H, He L, Lu K, Sarmah A, Li J, et al. Using biochar for remediation of soils contaminated with heavy metals and organic pollutants.Environ Sci Pollut Res.2013;20:8472-83.https://doi.org/10.1007/s11356-013-1659-0

23. De Figueiredo CC, Chagas JKM, da Silva J, Paz-Ferreiro J. Short-term effects of a sewage sludge biochar amendment on total and available heavy metal content of a tropical soil. Geoderma. 2019;344:31-9. https://doi.org/10.1016/j.geoderma.2019.0-1.052

24. Chintala R, Mollinedo J, Schumacher TE, Malo DD, Julson, JL. Effect of biochar on chemical properties of acidic soil. Arch Agron Soil Sci. 2014;60(3):393-404. https://doi.org/10.1080/03650340.2013.789870

25. Liu Z, Dugan B, Masiello CA, Gonnermann HM. Biochar particle size, shape, and porosity act together to influence soil water properties. Plos One. 2017;12(6):e0179079,1-19. https://doi.org/10.1371/journal.pone.0179079

26. Gorovtsov AV, Minkina TM, Mandzhieva SS, Perelomov LV, Soja G, Zamulina IV, et al. The mechanisms of biochar interactions with microorganisms in soil. Environ Geochem Health. 2020;42:2495-518. https://doi.org/10.1007/s10653-019-00412-5

27. Kong P, Lea-Cox JD, Hong CX. Effect of electrical conductivity on survival of Phytophthora alni, P. kernoviae and P. ramorum in a simulated aquatic environment. Plant Pathol. 2012;61(6):1179-86. https://doi.org/10.1111/j.13653059.2-012.02614.x

28. Figueiredo C, Lopes H, Coser T, Vale A, Busato J, Aguiar N, et al. Influence of pyrolysis temperature on chemical and physical properties of biochar from sewage sludge. Arch Agron Soil Sci. 2018;64(6):881-9. https://doi.org/10.1080/03650340.2017.1407870

29. Jaiswal AK, Elad Y, Graber ER, Frenkel O. Rhizoctonia solani suppression and plant growth promotion in cucumber as affected by biochar pyrolysis temperature, feedstock and concentration. Soil Biol Biochem. 2014;69:110-8. https://doi.org/10.1016/j.soilbio.2013.10.051

30. Akhter A, Hage-Ahmed K, Soja G, Steinkellner S. Compost and biochar alter mycorrhization, tomato root exudation, and development of Fusarium oxysporum f.sp. lycopersici. Front Plant Sci. 2015;6(529):1-13. https://doi.org/10.3389/fpls.20-15.00529

31. Brasil. Ministério da Agricultura, Pecuária e Abastecimento. Manual de métodos analíticos oficiais para fertilizantes e corretivos / Ministério da Agricultura, Pecuária e Abastecimento. Secretaria de Defesa Agropecuária. - Brasília: MAPA. 2017. 240 p.

32. Swift RS. Organic matter characterization. In: Sparks, D. L., Page, A. L., Helmke, P. A., Loeppert, R. H. (Eds.), Methods of Soil Analysis Part 3 - Chemical Methods. Soil Science Society of America. American Society of Agronomy, Madison, WI; 1996. p. 1011-69.

33. Yeomans JC, Bremner JM. A rapid and precise method for routine determination of organic carbon in soil. Comm Soil Sci Plant Anal. 1988;19:1467-76. https://doi.org/10.1080/00103628809368027

34. Da Silva FC. Manual de Análises Químicas de Solos, Plantas e Fertilizantes, 2nd ed. Embrapa Informação Tecnológica: Brasília, Brasil, 2009. 627 p.

35. IBM CORP. Released 2015. IBM SPSS Statistics for Windows, Version 23.0. Armonk, NY: IBM Corp. 2015.

36. Systat Software. SigmaPlot for Windows. (2013). Version 12.5 (SPSS Inc., Point Richmond, CA, USA).

37. Rogovska N, Laird D, Leandro L, Aller D. Biochar effect on severity of soybean root disease caused by Fusarium virguliforme. Plant Soil. 2017;413:111-26. https://doi.org/10.1007/s11104-016-3086-8

38. Zwart DC, Kim SH. Biochar amendment increases resistance to stem lesions caused by Phytophthora spp. in tree seedlings. HortScience. 2012;47:1736-40. https://doi.org/10.21273/HORTSCI.47.12.1736 
39. Frenkel O, Jaiswal AK, Elad Y, Lew B, Graber ER. The effect of biochar on plant diseases: what should we learn while designing biochar substrates? J Environ Eng Landsc Manag. 2017;25(2):105-13. https://doi.org/10.3846/16486897.2017.1307202

40. Graber ER, Frenkel O, Jaiswal AK, Elad Y. How may biochar influence severity of diseases caused by soilborne pathogens? Carbon Manag. 2014;5(2):169-83. https://doi.org/10.1080/17583004.2014.913360

41. De Araujo AS, Blum LEB, de Figueiredo CC. The synergistic effect of sewage sludge biochar and Trichoderma harzianum on soybean yield. Aust J Crop Sci. 2019;13(07):1183-7. https://doi.org/10.21475/ajcs.19.13.07 p.1-779

42. Gatch EW, Du Toit LJ. Limestone-mediated suppression of Fusarium wilt in spinach seed crops. Plant Dis. 2017;101(1):81-94. https://doi.org/10.1094/PDIS-04-16-0423-RE

43. Zong Y, Wang Y, Sheng Y, Wu C, Lu S. Ameliorating soil acidity and physical properties of two contrasting texture Ultisols with wastewater sludge biochar. Environ Sci Pollut Res. 2018;25(26):25726-33. https://doi.org/10.1007/s11356-017-9509-0

44. Serrano MS, de Vita P, Fernández-Rebollo P, Hernández MES. Calcium fertilizers induce soil suppressiveness to Phytophthora cinnamomic root rot of Quercus ilex. Eur J Plant Pathol. 2012;132:271-9. https://doi.org/10.1007/s10658-011-9871-6

45. Zhang Y, Zhao L, Feng Z, Guo H, Feng H, Yuan Y, et al. The Role of a New Compound Micronutrient Multifunctional Fertilizer against Verticillium dahliae on Cotton. Pathogens. 2021;10(81):1-14. https://doi.org/10.3390/pathogens 10010081

46. Khanmohammadi Z, Afyuni M, Mosaddeghi MR. Effect of pyrolysis temperature on chemical and physical properties of sewage sludge biochar. Waste Manag Res. 2015;33(3):275-83. https://doi.org/10.1177/0734242X14565210

47. Yuan H, Lu T, Huang H, Zhao D, Kobayashi N, Chen Y. Influence of pyrolysis temperature on physical and chemical properties of biochar made from sewage sludge. $J$ Anal Appl Pyrolysis. 2015;112:284-9. https://doi.org/10.1016/j.jaap.2015.01.010

48. Copley TR, Aliferis KA, Jabaji S. Maple bark biochar affects Rhizoctonia solani metabolism and increases dampingoff severity. Phytopathology. 2015;105(10):1334-46. https://doi.org/10.1094/PHYTO-08-14-0231-R

49. Heck DW, Ghini R, Bettiol W. Deciphering the suppressiveness of banana Fusarium wilt with organic residues. Appl Soil Ecol. 2019;138:47-60. https://doi.org/10.1016/j.apsoil.2019.02.021

50. Sani MNH, Hasan M, Uddain J, Subramaniam S. Impact of application of Trichoderma and biochar on growth, productivity and nutritional quality of tomato under reduced N-P-K fertilization. Ann Agric Sci. 2020;65(1):107-15. https://doi.org/10.1016/j.aoas.2020.06.003

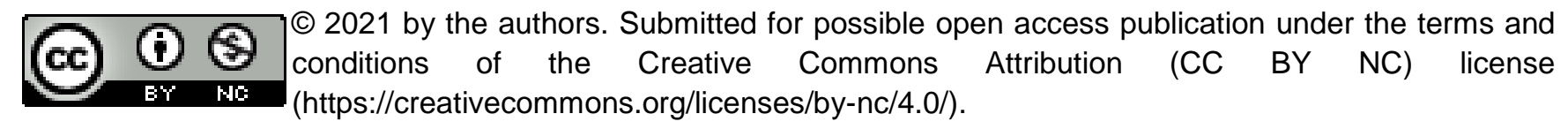

